\title{
Human Cytomegalovirus Immune Globulin
}

National Cancer Institute

\section{Source}

National Cancer Institute. Human Cytomegalovirus Immune Globulin. NCI Thesaurus. Code C80826.

A sterilized solution containing immunog lobulins (IGs) against cytomegalovirus (CMV) that is derived from human plasma of donors infected with CMV and can be used for passive immunization against CMV. Upon administration, human CMVIG is used to help prevent or treat infection by CMV. 